\title{
A global interactive database of rift obliquity for the last $200 \mathrm{My}$
}

\author{
Sascha Brune $e^{a, b}$, Simon E. Williams ${ }^{a}$, Nathaniel P. Butterworth ${ }^{a}$, Xiaodong \\ Qin $^{a}$, and R. Dietmar Müller ${ }^{a}$ \\ ${ }^{a}$ EarthByte Group, School of Geosciences, University of Sydney, NSW 2006, Australia. \\ ${ }^{\mathrm{b}}$ German Research Centre for Geosciences GFZ, 14473 Potsdam, Germany.
}

Oblique rifting takes place between two divergent continental plates when their relative velocity is at an angle to the plate boundary. Rift obliquity has a strong impact on basin structure, since normal faults do not strike perpendicular to the extension direction, but they are rotated during the initial rift stage by half the angle of obliquity (the angle between the extension direction and the rift trend normal). Hence, extension-parallel seismic profiles record apparent fault dips that are less steep than true dip angles, which complicates kinematic fault reconstructions. The only way to understand the tectonic evolution of obliquely rifted margins is $3 \mathrm{D}$ basin modeling that accounts for the local history of extension obliquity.

Here we present a kinematic rift obliquity model via a web-interface that allows the evolution of rift obliquity to be quantified at any location within rifted margins that have formed since $200 \mathrm{Ma}$. The underlying global database of rift obliquity is populated using the latest global plate tectonic reconstructions and passive margin outlines. We extract the angle of obliquity from a global plate model via pyGPlates, a recently developed Python library that allows scriptbased access to the plate reconstruction software GPlates. In order to pinpoint continental break-up and as a proxy for the local trend of former rift systems, we use an updated global set of boundaries between continental and oceanic crust (COBs).

Analysing the entire length of rift systems worldwide that were active during the last $200 \mathrm{My}$, we find a mean obliquity of $\sim 40^{\circ}$, with a standard deviation of $25^{\circ}$. More than $75 \%$ of all rift segments exceeded an obliquity of $20^{\circ}$ highlighting the fact that oblique rifting is the rule, not the exception. Focussing on Australia, we show that segments of the Western Australian margin formed at very high angles of $40^{\circ}$ to $90^{\circ}$ during separation of India and Australia. Rifting between Australia and Antarctica involved a protracted extension history involving two stages with $\sim 25^{\circ}$ prior to $100 \mathrm{Ma}$ followed by more than $50^{\circ}$ obliquity until break-up. Eastward motion of the Lord Howe rise generated the eastern Australian margin with moderate obliquity of $\sim 30^{\circ}$. Considering that most conceptual models of rift evolution assume 2D deformation, we here quantify the degree to which 2D rift evolution concepts are applicable, and highlight the importance of 3D basin modelling where oblique rifting is the dominant mode of deformation. 